\title{
DEMOCRACIA E PLANEJAMENTO TERRITORIAL: Desenvolvimento urbano de Goiânia e Planos Diretores Participativos na RMG
}

\section{DEMOCRACY AND TERRITORIAL PLANNING: Goiânia Urban Development and Collaborative Master Plans in the MRG}

\section{DEMOCRACIA Y PLANEAMIENTO TERRITORIAL: Desarrollo urbano de Goiânia y el Manejo Planea Participativos en el MRG}

\author{
Adão Francisco de Oliveira \\ Professor da Universidade Federal do Tocantins - UFT. \\ Doutorando em Geografia pela UFG. Pesquisador do Observatório das Metrópoles - núcleo Goiânia. \\ Endereço: Q. 406 Norte, alameda 05, lote 04, apto. 03, Palmas - TO, CEP: 77.000-000. \\ E-mail: adaofrancisco@gmail.com \\ Eguimar Felício Chaveiro \\ Professor do Programa de Pesquisa e Pós-Graduação em Geografia do IESA/UFG. \\ Pesquisador do Observatório das Metrópoles - núcleo Goiânia. \\ E-mail: eguimar@hotmail.com \\ Germana Pires Coriolano \\ Mestranda em Desenvolvimento Regional/UFT \\ e pesquisadora do Observatório das Metrópoles - núcleo Goiânia. \\ E-mail: gerpires@gmail.com \\ Juliano Martins Rodrigues \\ Mestre em Sociologia pela UFG e pesquisador do \\ Observatório das Metrópoles - núcleo Goiânia. \\ E-mail: Juliano_cs@ hotmail.com
}

\section{Resumo}

A deterioração da qualidade de vida nas grandes cidades brasileiras tem levado à reflexão um número razoável de pesquisadores das ciências sociais no Brasil nesse início de século. Embora já tivessem sido debatidas anteriormente, é no período da democratização dos anos 1980 que a problemática urbana no Brasil adquire um conteúdo propriamente político. Através do Movimento Nacional pela Reforma Urbana (MNRU), ganham destaque as reivindicações relativas aos níveis de injustiça social no meio urbano e as pressões pela democratização do planejamento e da gestão. Nessa perspectiva, os processos de definição das políticas urbanas estão, agora, demarcados por uma nova relação entre Estado e sociedade e a atuação dos agentes nos espaços de 
decisão e controle é orientada por novas formas e conteúdos. Neste estudo pretendemos identificar os conteúdos de participação popular e de democratização nos Planos Diretores Participativos de quatro municípios da Região Metropolitana de Goiânia, elaborados entre os anos de 2004 e 2008.

Palavras-chave: Democratização; Reforma Urbana; Estatuto da Cidade; Plano Diretor Participativo.

\begin{abstract}
The deterioration of the quality of life in the great Brazilian cities has taken to the reflection a reasonable number of researchers of social sciences in Brazil in this beginning of century. Although they already had been debated previously, it is in the period of the democratization of years 1980 that the urban problematic in Brazil acquires a content properly politician. Through the National Movement for Urban Reform (MNRU) (MNRU) the claims gain prominence relative to the levels of social injustice in the urban way, as well as the pressures for the democratization for planning and management. In this perspective, the processes of definition of the urban politics are, now, demarcated for a new relation between State and society. In the same time, the performance of the agents in the spaces of decision and control is guided by new forms and contents. This study aimed to identify the contents of popular participation and democratization in Participative Director Plans from four cities of Goiânia's Metropolitan Region, elaborated between the years of 2004 and 2008.
\end{abstract}

Key words: Democratization; Urban Reform; Statute of the City; Participative Director Plan.

\title{
Resumen
}

La deterioración de la calidad de la vida en las grandes ciudades brasileñas ha llevado la reflexión un número razonable de los investigadores de ciencias sociales en el Brasil en este principio del siglo. Aunque habían sido discutidos ya previamente, es en el período de la democratización de los años el an o 80 que problemático de el urbano en el Brasil adquiere a político del contenido correctamente. A través del movimiento nacional para Reforma Urbana (MNRU), ganan la prominencia que el pariente demanda a los niveles de la injusticia social de la manera urbana y de las presiones para la democratización él planeamiento y de la gerencia. En esta perspectiva, los procesos de la definición de la política urbana, ahora, se demarcan para una nueva relación entre el estado y las nuevos formas y contenido dirige a la sociedad y el funcionamiento de los agentes en los espacios de la decisión y del control. En este estudio nos preponemos identificar al contenido de la participación y de la democratización populares en los planes de manejo Participativos de cuatro ciudades del metropolitano de la región de Goiânia, elaborado entre los años de 2004 y 2008.

Palabras-clave: Democratización; La reforma Urbana; Estatuto de la ciudad; Plan de manejo Participativo. 


\section{Introdução}

A deterioração da qualidade de vida nas grandes cidades brasileiras tem levado à reflexão um número razoável de pesquisadores das ciências sociais no Brasil nesse início de século. A cidade, presente nos estudos e programas de pesquisas, é visivelmente demarcada por ocorrências empíricas relacionadas à violência, às condições precárias de moradia, à saúde e à gestão pública. Essa situação é agravada, desde a metade do século passado, devido às explosões demográficas e o fenômeno da metropolização, o qual atinge diversos pontos no território brasileiro.

Embora já tivessem sido debatidas anteriormente, é no período da democratização dos anos 1980 que a problemática urbana no Brasil adquire um conteúdo propriamente político. Através do Movimento Nacional pela Reforma Urbana (MNRU), ganham destaque as reivindicações relativas aos níveis de injustiça social no meio urbano e as pressões pela democratização do planejamento e da gestão (SOUZA, 2003). O principal efeito da atuação do movimento foi a inscrição de instrumentos legais com essa orientação na Constituição de 1988.

Ao analisarmos os artigos da Constituição Federal que tratam da política urbana - 182 e 183 - percebemos a presença dos dispositivos principais que regulamentam os dispositivos de controle e ordenamento urbano. A efetiva regulamentação desses artigos encontra-se, no entanto, na lei $\mathrm{n}^{\mathrm{o}}$. 10.257, de 10 de julho de 2001 - o Estatuto da Cidade. As diretrizes do Estatuto da Cidade, de forma geral, podem ser vistas assim: (a) as clássicas, referentes ao planejamento e uso do solo urbano; (b) as referentes à ação do poder público; (c) as que se referem à função social da propriedade; (d) as que dizem respeito à oportunidade de propriedade urbana e à moradia, sobretudo pelas populações de baixa renda; (e) as que tratam da relação entre poder público e sociedade através da participação individual e comunitária; e (f) aquelas relativas às necessidades de proteção do meio ambiente, do patrimônio histórico, etc. (CARDOSO e RIBEIRO, 2003).

Uma das diretrizes no Art. $2^{\circ}$, inciso II, diz respeito à participação popular na gestão e no planejamento urbano:

Gestão democrática por meio da participação da população e de associações representativas dos vários segmentos da comunidade na formulação, execução e acompanhamento de planos, programas e projetos de desenvolvimento 
urbano (ESTATUTO DA CIDADE, 2001).

Esse novo quadro institucional reorienta a atuação dos agentes coletivos dentro do campo político citadino, uma vez que faz despertar o interesse público por questões de desenvolvimento urbano, principalmente aquelas que são pontuais e que demarcam cotidianamente a vida urbana, tais como a ocupação do solo, as políticas habitacionais e o transporte coletivo.

Ribeiro e Cardoso (2003) entendem que o espaço urbano é uma arena onde defrontam interesses de benefícios em termos da geração de rendas e obtenção de ganhos e que, portanto, se referem basicamente ao interesse de ordem econômica. Por outro lado, demandas por melhores condições materiais e simbólicas de vida se manifestam em um quantitativo crescente de pessoas. O cenário daí derivado evoca a discussão tanto dos problemas urbanos quanto das questões que envolvem a mobilização política e a participação coletiva nas cidades.

Nessa perspectiva, entendemos que os processos de definição das políticas urbanas estão, agora, demarcados por uma nova relação entre Estado e sociedade (GOHN, 2003; NOGUEIRA, 2004; SANTOS JÚNIOR, 2001) e a atuação dos agentes nos espaços de decisão e controle são orientadas por novas formas e conteúdos. Isso porque o arranjo institucional proporcionou a emergência de formatos diferenciados de espaços decisórios nas cidades. Neste estudo se pretende identificar os conteúdos de participação popular e de democratização nos Planos Diretores Participativos de Goiânia e de mais três municípios de sua Região Metropolitana - RMG, elaborados entre os anos de 2004 e 2008. Os municípios são: Aparecida de Goiânia, Senador Canedo e Trindade. A escolha desses municípios se explica pelo fato de serem eles aqueles que vivem a integração metropolitana, possível em torno do seu núcleo, a capital do Estado.

Como estratégia analítica, se opta nesse estudo, primeiramente, por destacar a formação do espaço urbano de Goiânia, núcleo metropolitano e entorno do qual se constituiu a única região metropolitana do Estado de Goiás, destacando as contradições e especificidades que o qualificam, pressupondo uma forte articulação entre a dinâmica espacial e a definição das relações políticas. O fenômeno metropolitano da RMG é fundamentalmente tributário do desenvolvimento e da expansão urbanas de Goiânia, 
cidade que também encerra a condição de capital do Estado e de economia mais pujante, com destaque para os setores terciário (com destaque à prestação de serviços) e secundário, sendo que para este setor vive-se, nas duas últimas décadas, uma descentralização de alojamento das indústrias nos demais municípios da região.

Assim, a problemática urbana e metropolitana gira em torno da dinâmica espacial de Goiânia, que articula os demais municípios da região numa rede de integração, sendo que os municípios que mais contribuem para a efetivação dessa integração são os supracitados, alvos dessa análise. As resoluções políticas cunhadas nos fundamentos democráticos instituídos a partir da Constituição de 1988 para lidar com os problemas advindos de tal problemática são apresentadas principalmente a partir da capital.

Por fim, para clarear a discussão, se indica através de um quadro expositivo a dinâmica de funcionamento da experiência em questão.

\section{A formação do espaço urbano de Goiânia}

Construída numa localização estratégica no Estado de Goiás para alojar não só o centro do poder político como também do desenvolvimento econômico, Goiânia satisfez a uma dupla dimensão de interesses. A primeira é a idealizada pelo pioneiro Pedro Ludovico Teixeira na representação política dos produtores agropecuários do sul/sudoeste do Estado. Nesta, a nova capital do Estado estaria topicamente distante da influência das velhas oligarquias goianas - influência esta exercida a partir da cidade de Goiás -, sob liderança da família Caiado, e atenderia com mais precisão a demanda por infra-estrutura e serviços públicos das regiões sul e sudoeste do Estado, articuladas à economia de mercado dirigida pelo centro-sul do país (CAMPOS, 2002; CHAUL, 2000, 2000; OLIVEIRA, 2002b). A segunda dimensão é aquela dirigida por Getúlio Vargas, que via Goiânia como um entreposto para a concretização do projeto de segurança nacional e, ao mesmo tempo, um trampolim para a articulação do centro-norte amazônico à economia de mercado, como pretendiam os investidores do capital (BERNARDES, 1998; CHAUL, 2000; OLIVEIRA, id.). Goiânia seria, nesta perspectiva, um instrumento fundamental da política da "Marcha para o Oeste".

Assim, entre as décadas de 1930 e 1960, a capital goiana foi o palco de decisões 
políticas que, por um lado, viabilizaram o avanço da fronteira econômica para fora de seu território, rumo ao norte do país - integrando todo o território goiano, no geral, à rede de mercado capitalista, e potencializando seu "papel" na divisão regional do trabalho (BORGES, 2000). Por outro lado, para que Goiânia suportasse o peso de sua representação, tais decisões a produziram razoavelmente na sua dimensão pública para, a partir de 1950, permitirem a privatização das iniciativas de seu desenvolvimento. A este respeito, é interessante o que dizem alguns estudiosos sobre a cidade, ao conceituarem o período. Para Pastore (1984), o período significou "a privatização do parcelamento do solo em Goiânia"; Chaves (1985) o compreende como sendo de "privatização do espaço e conflitos urbanos"; Moraes (1991) o identifica como sendo a "fase de ampliação do espaço".

Desta forma, a gestão pública sobre a capital do Estado de Goiás aproximava a lógica de desenvolvimento da cidade à nova fase do desenvolvimentismo nacional, que garantiu privilégios à iniciativa privada nas ações sobre os territórios, resumindo-se à montagem de infra-estrutura básica e de serviços e a mediar interesses econômicos. O impacto dessa condição política sobre Goiânia foi significativo, haja vista que sobre esta cidade recaia uma intensa procura por moradia e alternativa de sobrevivência de famílias retirantes da zona rural e de pequenas cidades sem grandes perspectivas, tanto de Goiás quanto de outros Estados, principalmente do Nordeste (em particular do Maranhão e da Bahia) e de Minas Gerais.

O resultado de tudo isso foi um intenso crescimento demográfico de Goiânia, de acordo com os seguintes índices: de 1950 a 1960, 187,5\%; de 1960 a 1970, 153,9\%; e de 1970 a 1980, 109,7\%. Ou seja, Goiânia saltou de uma população de 53.389 habitantes em 1950 para 817.343 habitantes em 1980 (SOUZA, 1996, p. 38, apud OLIVEIRA, 2002b, p. 71).

Nestas dimensões, Goiânia viu não só um aumento do sítio urbano, como também uma diversidade social aumentada, pois passou a agregar "uma variabilidade de possibilidades de trabalho, de níveis de consumo, de papéis sociais e de proveniência de pessoas" (COSTA, 2005, p. 80).

Essa trajetória de crescimento nos faz compreender a cidade de Goiânia como uma metrópole precoce. Idealizada e concretamente iniciada no limiar dos anos de 1930, Goiânia encerrou o século XX na condição institucional de metrópole, tendo 
atingido em 2005, segundo estimativas do IBGE, aproximadamente 1,2 milhão de habitantes, sendo que sua região metropolitana, neste mesmo ano, constituída por mais 11 municípios ${ }^{1}$, alcançou 1.934 .771 habitantes.

A complexidade de processos sociais que acompanham o fenômeno da metropolização deu contornos bem definidos ao que hoje compreendemos como Região Metropolitana de Goiânia. O que foi moldado resultou na constituição de uma série de novos problemas socioterritoriais, os quais se traduzem nos espaços diferenciados da cidade pólo e de seu entorno.

\section{Segregação socioespacial e as lutas políticas na cidade}

A dinâmica percebida na formação do espaço urbano de Goiânia, e que hoje predomina nas grandes cidades brasileiras, é assinalada por um fenômeno identificado na maioria dos estudos urbanos como sendo efeitos da segregação espacial.

Villaça (1998) entende que a alta concentração de camadas sociais em determinada parcela do espaço urbano caracteriza a segregação residencial. Em seu argumento, a segregação espacial na cidade mostra-se necessária para que exista uma dominação pelo espaço urbano e para que, através dessa dominação, haja apropriação diferenciada do produto do trabalho, entendendo que o espaço urbano é o produto do trabalho de todos os que habitam e trabalham na cidade.

Caldeira (2000), ao analisar o processo de urbanização de São Paulo, identifica diferentes momentos de consolidação da segregação urbana. No primeiro, diferentes grupos sociais se comprimem numa mesma área, sem a definição clara de áreas/bairros para determinados grupos. Este período vai do final do século XIX até os anos 40; outro momento, que vai até o início dos anos 1980, é caracterizado pela relação centroperiferia, que estabelece regiões para cada grupo social, sendo que as classes mais elevadas ocupam o centro e suas imediações e os pobres a periferia; no momento atual,

\footnotetext{
${ }^{1}$ A Região Metropolitana de Goiânia - RMG foi criada em 1999 pela Lei Complementar no 27, que instituiu como finalidade "integrar a organização, o planejamento e a execução de funções públicas de interesse comum dos municípios dela integrantes" (cf. art. $2^{\circ}$ ). Faziam parte dela 11 municípios, sendo eles: Abadia de Goiás, Aparecida de Goiânia, Aragoiânia, Goianápolis, Goiânia, Goianira, Hidrolândia, Nerópolis, Santo Antônio de Goiás, Senador Canedo e Trindade. Em 2004, a Lei Complementar $n^{\circ} 048$ acrescentou a ela o município de Bela Vista de Goiás e, em 2005, a Lei Complementar no 54 integrou a ela o município de Guapó, de modo que o seu total de municípios passou para 13.
} 
que rompe com os limites de áreas de circunscrição, embora o padrão centro-periferia ainda ocorra, destaca-se o padrão dos enclaves fortificados (condomínios fechados), onde a noção de separação de classes torna-se sem sentido, tendo-se que falar somente em excluídos e incluídos, que convivem lado a lado separados por muros.

Atualmente, o debate aumenta em complexidade, sendo ampliado, sobretudo, pelas modificações que operam em níveis globais e das modificações que o processo de metropolização acarreta na realidade urbana brasileira. Segundo Ribeiro (2005), as causas macro-estruturais estão ligadas à globalização que impõe novos modelos e paradigmas às políticas urbanas, por um lado, e, por outro, reordena a economia a partir da concentração de investimentos e renda. Tudo isso molda a estrutura social de forma polarizada. No caso da metropolização, ocorre esvaziamento e estagnação de áreas centrais das maiores cidades, com a emergência de novas dinâmicas imobiliárias, marcadas principalmente pela inclusão dos enclaves residenciais de alta renda, fortificados e reclusos através de barreiras físicas bem visíveis, como muros altos e cercas elétricas (RIBEIRO, 2005).

A forma com que a cidade é estruturada socialmente é premissa fundamental para se delimitar o conceito de segregação. A diferenciação social se converte em espaços também diferenciados e o entrelaçamento desses dois tipos de relação social é determinado por hierarquias definidas a partir, então, da localização espacial e do acesso a bens materiais e simbólicos. A segregação espacial, nessas bases, produz uma dinâmica de causação circular da pobreza e o efeito disto é a alta concentração de grupos em situação de vulnerabilidade em territórios homogêneos, por um lado, e a concentração de categorias superiores, em outro (RIBEIRO, op. cit.).

Ruben Katzman (2005), embora não fazendo uso da mesma terminologia, demonstra de forma bastante lúcida essa relação, mostrando a existência de um certo círculo vicioso entre pobreza e concentração espacial ${ }^{2}$. Para esse autor, o isolamento de alguns estratos pobres das populações urbanas se converte em um obstáculo importante para o acúmulo de ativos necessários para deixar de ser pobre, fazendo com que a pobreza urbana socialmente isolada se constitua em um caso paradigmático da exclusão social. Nessa linha, o resultado mais significante é a manutenção de vínculos frágeis entre a população destituída e as instituições que detêm o controle das normas e valores 
dominantes na sociedade, como no caso do sistema educacional.

Por outro lado, ocorre também um cercamento cultural e simbólico, que fica estereotipado nas concentrações espaciais. Esse processo gera padrões de conduta e cognição singulares. Tal perspectiva é trazida por Wacquant (2004), que apresenta a noção de gueto para essas formações sociais.

A partir dessas considerações, entendemos que o efeito das diferenças que se traduzem no espaço tem um retorno imediato para a dinâmica social. Isso porque, além de acarretar modificações significativas nas relações produtivas com recolocação da população no mercado informal, diminui as chances de protagonismo da população segregada, diminui os ativos necessários para reforçar os vínculos com as instituições e engendra padrões de conduta e comportamento que pouco contribuem para a afirmação de direitos e de princípios de justiça social. Por isso, a confluência entre espaço demarcado pelo fenômeno da segregação e os processos políticos concomitantes são as variáveis preponderantes nesta reflexão.

As lutas políticas de conteúdo predominantemente urbano são recentes no Brasil. A questão urbana só foi agregada à agenda política nacional, como entendem Bonduki e Kowarick (1988), a partir dos anos de 1970. Nesse deslocamento, as lutas e reivindicações que se desenvolveram em busca de benefícios urbanos, acesso à terra, habitação e bens de consumo coletivos, passam a se relacionar às conjunturas políticas. Isso porque a segregação, enquanto forma de domínio político, cristalizou e passou a dominar as relações de poder na cidade. A chamada espoliação urbana, como afirma Kowarick (1979), fixou o mito de uma sociedade amorfa, incapaz intelectualmente de reivindicar e lutar por direitos primários, relacionados, sobretudo, às condições de trabalho e moradia nas metrópoles.

Para Gohn (2003), a transformação no cenário político das metrópoles, através da redemocratização, instaura um novo vínculo entre sociedade e Estado, marcado, sobretudo, pela ascensão de movimentos sociais que, mesmo influenciados por vetores de despolitização e individualismo, possibilitaram o estabelecimento e a consolidação de novos espaços de reivindicação. Esses espaços se traduzem em fóruns permanentes, audiências públicas, conselhos gestores, etc. A dinâmica, agora assinalada pela participação popular, é definida a partir da atuação de uma heterogeneidade de

\footnotetext{
${ }^{2}$ Para o autor, a situação é gerada pela precariedade ou inexistência dos vínculos com o mundo do
} 
entidades, compostas por diferenciadas visões de mundo, valores, projetos sóciopolíticos e culturais e cultura política em si.

A nova relação entre sociedade e Estado demarca também as políticas urbanas. Por isso as prerrogativas participativas, presentes no ideário da reforma urbana, refletem-se na gestão e no planejamento urbano. As administrações de esquerda nos municípios brasileiros a partir dos anos de 1990 instauraram, segundo Cardoso e Ribeiro (2003), o "planejamento politizado".

Ao lado desse planejamento urbano politizado se consolida, também, um amplo espaço de luta política que situa diferentes agentes na defesa de interesses. O espaço urbano passa a ser uma arena de luta onde se concentra de um lado agentes interessados na apropriação de renda e ganhos de origem produtiva ou comercial, e de outro os que lutam por melhores condições materiais e simbólicas de vida (CARDOSO E RIBEIRO, 2003).

Ao pressupormos a atuação de uma complexa rede de agentes coletivos agarrados a referências diversas, resta saber como se configura os espaços de ação desses agentes. Isso é tarefa das teorias democráticas atuais.

\section{Democracia, condição democrática e poliarquia}

Atualmente, é bastante rico e não menos extenso os debates sobre democracia. A complexificação social impõe novos desafios às teorias democráticas (Costa, 2001), o que concorre para o estabelecimento de escolhas teóricas mais aproximadas com os objetivos das investigações. Ao admitirmos que a indagação que aqui fazemos sobre a mobilização política nas questões urbanas está relacionada com um quadro institucional específico, procedemos na análise das instituições políticas como forma de antecipar as nossas conclusões.

Dahl (1997) admite uma distinção entre democracia, como ideal regulador, e poliarquias, como exemplares empíricos da descrição. Neste modelo existe uma combinação entre cooperação e conflito, pressupondo a existência de instituições visíveis para os agentes, como eleições, partidos e parlamentos.

Tal percepção se baseia na suposição de que o governo dê respostas às

trabalho pela redução dos espaços públicos que geram relações informais de convívio. 
preferências dos seus cidadãos, considerados como politicamente iguais. Assim, aos cidadãos devem ser garantidas algumas (oportunidades?) na sua plenitude, as quais incluem: a formulação de preferências; expressão das preferências aos demais membros da comunidade coletiva e ao governo através da ação coletiva e individual; e ter as preferências igualmente consideradas na conduta do governo, independentemente do conteúdo ou da fonte (DAHL, 1997, p. 26).

A forma como os governos geram estas condições relaciona-se com os regimes democráticos, existentes numa ampla variedade de situações. Por isso, Dahl (1997, p. 31) prefere designar as experiências reais dos sistemas políticos de poliarquia. Por esta, se entende "um regime fortemente inclusivo e amplamente aberto à contestação política". Por regime aberto se entende a liberalização da competição política por ato institucional, bem como o reconhecimento da igualdade de direitos e a aceitação dos resultados da competição. Já por regime de inclusividade, se entende a participação social em eleições e em cargos públicos eletivos, bem como na sua organização social, também com garantia de direitos. Compreende-se melhor a poliarquia na contraposição de regimes contrários, tais como: 1) a hegemonia fechada; 2) a hegemonia aberta; e 3) a oligarquia competitiva.

Resumidamente, a proposta teórica de Dahl é enquadrar realidades democráticas específicas ao seu modelo de análise. As variáveis principais nesse caso são: 1) a amplitude do direito de participação e 2) a existência do direito à contestação pública.

No caso de Goiânia, investigar os canais de participação na cidade possibilita o estabelecimento de um quadro esclarecedor no nível poliárquico assumido nessa realidade. Resguardadas as devidas proporções, a experiência eleita para este estudo serve de indicador para essa aproximação.

\section{Inscrição democrática nos Planos Diretores Participativos da RMG}

A realidade paisagística de Goiânia hoje, frente ao seu desenvolvimento histórico, deixa qualquer analista surpreso. Em 75 anos de existência, a cidade atingiu o status de metrópole e passou a contar com uma população de 1.265.394 habitantes, sendo que a população de sua Região Metropolitana, composta por 13 municípios, é de 2.063.744 habitantes, de acordo com a estimativa/contagem do IBGE 2007 (Sistema 
IBGE de Recuperação Automática - SIDRA).

TABELA 1: POPULAÇÃO DA REGIÃO METROPOLITANA DE GOIÂNIA POR MUNICÍPIO E SEU IDH

RMG: ÍNDICE DE DESENVOLVMENTO HUMANO

\begin{tabular}{l|r|c|c}
\hline \multicolumn{1}{c|}{ Municipio } & População & IDH (PNUD 2000) & Nível \\
\hline Abadia de Goiás & 6.182 & 0,742 & Médio \\
\hline Aparecida de Goiânia & 494.919 & 0,764 & Médio \\
\hline Aragoiânia & 7.589 & 0,759 & Médio \\
\hline Bela Vista de Goiás & 21.466 & 0,744 & Médio \\
\hline Goiânia & 1.265 .394 & 0,832 & Elevado \\
\hline Goianápolis & 11.580 & 0,689 & Médio \\
\hline Goianira & 25.647 & 0,740 & Médio \\
\hline Guapó & 13.974 & 0,729 & Médio \\
\hline Hidrolândia & 14.577 & 0,736 & Médio \\
\hline Nerópolis & 20.120 & 0,785 & Médio \\
\hline Santo Antônio de Goiás & 4.129 & 0,749 & Médio \\
\hline Senador Canedo & 75.297 & 0,729 & Médio \\
\hline Trindade & 102.870 & 0,759 & Médio \\
\hline
\end{tabular}

Fonte: SIDRA/IBGE, 2007.

Obviamente, o sítio urbano da cidade cresceu para comportar tamanha população, o que é perceptível no conjunto de loteamentos que se tem empreendido hoje, no reaquecimento dos negócios com condomínios verticais e na expansão descentralizada dos condomínios horizontais fechados. Encarnando esse mesmo sentido de mudança, foi necessário abrir novas avenidas e racionalizar o trânsito para que Goiânia pudesse suportar o intenso fluxo de veículos que a circulam no cotidiano. Em alguns horários se verificam determinados pontos de estrangulamento do trânsito, haja vista a existência de gargalos que incidem na aproximação de áreas tradicionais que movimentam o mercado.

Além de ser o pólo, o epicentro da RMG, Goiânia é antes ainda a capital do Estado de Goiás, o que por si é suficiente para gerar uma constante peregrinação de pessoas, políticos e técnicos nos centros executores das políticas públicas: as secretarias de Estado. Não obstante, a sua especialização mercantil na oferta de serviços especializados, principalmente nos setores de facção têxtil e de saúde, a torna uma atração interestadual, em especial para os Estados do Norte e do Nordeste brasileiro e municípios do Estado de Minas Gerais. No que se refere ao setor de saúde, Goiânia tornou-se uma atração não só no serviço privado como também no público, o que 
consiste num grande problema para o município e para os poderes públicos municipal e estadual, conforme sugere o Plano Diretor de Regionalização da Saúde de Goiás PDR/GO, que destaca a necessidade de desconcentração dos serviços de saúde da capital do Estado. Com tais prerrogativas, essa cidade se converteu numa metrópole regional.

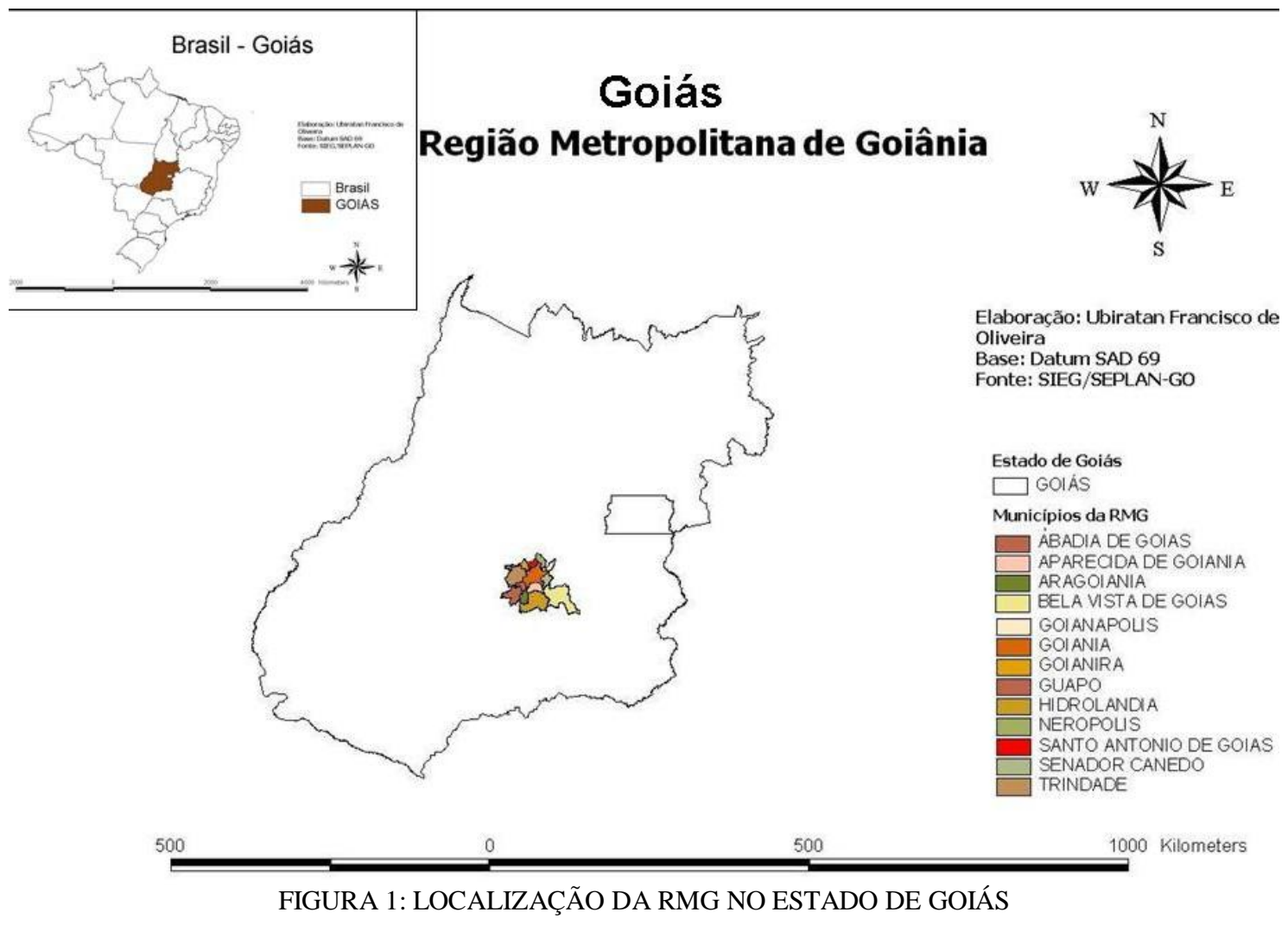

Cabe ressaltar que os elementos agregados na década de 2000 que refletem essa condição urbana são, eles próprios, fruto de todo um desenvolvimento histórico, que tem como principais fundamentos a ação da gestão pública na cidade associada, na década de 1950, aos princípios do desenvolvimentismo nacional, à construção de Brasília e à decorrente constituição de um eixo de desenvolvimento econômico entre esta e Goiânia, tornando-a num pólo de atração humana.

Com uma representação política e mercantil tão significativa, os últimos administradores públicos da cidade de Goiânia, desde o governo Darci Accorsi, do PT (1993-1996), têm buscado imprimir, a partir do planejamento estratégico, uma marca na perspectiva da concepção de image-making, gestada nos EUA a partir dos anos de 
1960, que tinha a intenção de afeiçoar as cidades à dinâmica do mercado, como nos apresenta Arantes (2007). Ao analisar a lógica dessa modalidade de planejamento, muito em voga principalmente a partir da reforma urbanística imposta à cidade de Barcelona, na Espanha, no início dos anos de 1990, essa autora o expõe como aquilo que

\begin{abstract}
Veio agravar ainda mais o inchaço cultural imperante desde que governantes e investidores passaram a desbravar uma nova fronteira de acumulação de poder e dinheiro - o negócio das imagens. O "tudo é cultura" da era que parece ter se inaugurado nos idos de 1960 teria pois se transformado de vez naquilo que venho chamando de culturalismo de mercado. De tal forma que a cultura - que nos primórdios da Era Industrial se cristalizara como esfera autônoma dos valores antimercado -, ao tornar-se imagem, quer dizer, representação e sua respectiva interpretação (como sabe qualquer gerente de marketing numa sociedade do espetáculo), acabou moldando, de um lado, indivíduos (ou coletividades "imaginadas") que se auto-identificam pelo consumo ostensivo de estilos e lealdade a todo tipo de marca; de outro, o sistema altamente concentrado dos provedores desses produtos tão intangíveis quanto fabulosamente lucrativos. Trocado em miúdos, esse o verdadeiro "poder da identidade". Daí a âncora identitária da nova urbanística (ARANTES, 2007, p. 16).
\end{abstract}

No caso de Goiânia, uma importante investida nesse sentido foi a de torná-la uma country city, no reboque da representação de que Goiás é um Estado eminentemente agropastoril ${ }^{3}$. A favor dessa investida está a indústria fonoaudiográfica, que promove constantemente duplas goianas de músicas sertanejas, presumivelmente lançadas na grande festa que é a exposição agropecuária da cidade.

Contudo, diante de uma análise mais atenta, não resta dúvida de que tudo seria de fato muito interessante e importante para a promoção da qualidade de vida do conjunto da população goianiense, não fosse o sentido balizar que orienta tais ações, pautado na expansão das possibilidades de mercado e regulado com base no ideário neoliberal. Assim,

\begin{abstract}
Destituída de uma visão de planejamento holístico, a cidade passou a ser vista pontualmente com a intenção de se requalificá-la, revitalizá-la, readaptá-la, revalorizá-la. Como resultado, se tem uma cidade-espetáculo, interessante o suficiente para atrair investimentos econômicos. Porém, o caráter classista de leitura e tratamento da cidade sob tais signos é explícito.
\end{abstract}

\footnotetext{
${ }^{3}$ A idéia de que Goiás é um Estado eminentemente agropastoril é falsa e desmentida pelos números de sua economia, que indicam a predominância das atividades industriais sobre todas as outras. Para verificar detalhes, ver a página eletrônica da SEPLAN/GO, no endereço: www.seplan.go.gov.br.
} 
A necessidade de atração de investimentos para a sua qualificação no "mercado global" faz das ações pontuais ações que reforçam a cidade formal, a cidade tratada, a bela cidade, a isotopia. [...] No entanto, como os espaços segregados não colaboram para esse tipo de promoção que se pretende das cidades, reforça-se o seu caráter segregado através de ações de confinamento territorial ou de polícia. Em outras palavras, a cidade informe é violentamente reprimida, seja material ou simbolicamente. Esse caráter classista da nova lógica de se pensar e planejar as cidades é velado pelo conjunto de propagandas que fabricam idéias e conceitos de que esse é o único caminho. Essa é a marca do neoliberalismo: a produção de um pensamento único para o planejamento e a gestão das cidades. Desenvolve-se um (falso) consenso a partir de um receituário de medidas e ações formulado nas agências multilaterais e financeiras internacionais (BM, FMI, BID, Habitat etc.) (OLIVEIRA et al., 2008, p. 6).

O que se depura de tais assertivas é que a cidade, tal qual se fez Goiânia, enquanto território da unidade básica das relações sociais, reflete toda a gama das artimanhas mercadológicas que definem o propalado fenômeno da globalização, sedimentado nos (des)princípios do neoliberalismo.

A avalanche ideológica do ideário neoliberal, ao mercantilizar a cidade, o seu território, e transformar o signo do gozo de direitos em mercadoria, tornando a condição cidadã em clientela, de forma sorrateira e sutil, minou, em Goiânia - um dos últimos bastiões da velha cultura política -, a cultura cívica. Uma das expressões dessa situação encontra-se exatamente no novo plano diretor elaborado para a cidade.

Forjado sob o designo de Plano Diretor Participativo, este instrumento do planejamento territorial de Goiânia, que teve sua elaboração iniciada ainda no governo de Pedro Wilson (2001-2004), só foi definitivamente aprovado na Câmara Municipal de Goiânia e sancionado pelo prefeito Íris Rezende em 2007. Na trajetória de sua elaboração, foram vários os percalços que marcaram o seu conteúdo, sendo que o debate arrefeceu de uma condição (pelo menos em pretensão) ampla e popular para uma amarração eminentemente técnico-política. Não obstante, considerando o escopo metropolitano de Goiânia, é fundamental verificar como que os planos diretores dos principais municípios da RMG, que a Goiânia se integram diretamente, também foram constituídos, ignorando os mesmos fundamentos democráticos. 
TABELA 2 - AVALIAÇÃO SINTÉTICA DO SISTEMA DE GESTÃO E PARTICIPAÇÃO DEMOCRÁTICA NOS PLANOS DIRETORES PARTICIPATIVOS DOS MUNICÍPIOS DA RMG - 2008

\begin{tabular}{|c|c|c|c|c|c|c|c|c|}
\hline \multirow[t]{2}{*}{ SSTTEMA DE GESTĀO E PARTICIPAÇĀO DEMOCRÁTKCA } & \multicolumn{2}{|c|}{ Goiânia } & \multicolumn{2}{|c|}{ Trindade } & \multicolumn{2}{|c|}{ Senador Canedo } & \multicolumn{2}{|c|}{$\begin{array}{c}\text { Aparecida de } \\
\text { Goiânia }\end{array}$} \\
\hline & Sim & Não & Sim & Não & Sim & Não & Sim & Nāo \\
\hline Previsāo de audièncias públicas obrigatórias & & $\mathrm{X}$ & & $\mathrm{X}$ & & $\mathrm{x}$ & & $\mathbf{x}$ \\
\hline $\begin{array}{l}\text { Definiçōes relativas às consultas públicas (plebiscito, referendo ou } \\
\text { outras) }\end{array}$ & & $\mathrm{x}$ & & $x$ & & $\mathrm{x}$ & $\mathbf{x}$ & \\
\hline Definiçōes relativas às conferèncias e sua periodicidade & & $\mathrm{x}$ & $\mathrm{x}$ & & $\mathrm{x}$ & & & $\mathbf{x}$ \\
\hline $\begin{array}{l}\text { Instituiçāo de conselho da cidade ou outros conselhos ligados à } \\
\text { política urbana }\end{array}$ & $x$ & & $\mathrm{x}$ & & $\mathrm{x}$ & & $\mathbf{x}$ & \\
\hline $\begin{array}{l}\text { Mecanismos de articulaçāo entre conselhos relativos à política } \\
\text { urbana }\end{array}$ & & $\mathrm{x}$ & & $x$ & & $\mathrm{x}$ & & $\mathbf{x}$ \\
\hline $\begin{array}{l}\text { Previsāo de participaçāo social e de entidades representativas na } \\
\text { formulaçāo, execuçāo e acompanhamento dos planos, programas e } \\
\text { projetos de desenvolvimento urbano }\end{array}$ & $x$ & & $\mathrm{x}$ & & $\mathrm{x}$ & & $\mathbf{x}$ & \\
\hline $\begin{array}{l}\text { Definiçāo de criaçāo de fóruns entre governo e sociedade para } \\
\text { debate de políticas urbanas }\end{array}$ & $\mathrm{x}$ & & & $\mathrm{x}$ & & $x$ & & $\mathbf{x}$ \\
\hline $\begin{array}{l}\text { Previsāo de inscriçāo no orçamento público municipal de instâncias } \\
\text { de participaçāo social }\end{array}$ & & $\mathrm{x}$ & & $\mathrm{x}$ & & $\mathrm{x}$ & & $\mathbf{x}$ \\
\hline $\begin{array}{l}\text { Definiçāo de formas de planejamento e execuçāo das açōes, } \\
\text { especialmente prevendo a participaçāo social }\end{array}$ & & $\mathrm{x}$ & & $\mathrm{x}$ & & $\mathrm{x}$ & $\mathbf{x}$ & \\
\hline Definiçāo no plano de outras instâncias de participaçāo & & $\mathrm{x}$ & & $\mathrm{x}$ & & $\mathrm{x}$ & $\mathbf{x}$ & \\
\hline
\end{tabular}

Fonte: Rede Nacional de Avaliação e Capacitação para Implementação dos Planos Diretores Participativos(2008); Plano Diretor do Município de Goiânia (Lei Complementar No 171, de 29 de maio de 2007); Plano Diretor do Município de Senador Canedo, 2006; Plano Diretor do Município de Trindade; Plano Diretor do Município de Aparecida de Goiânia (Lei Complementar N 004, de 30 de janeiro de 2002). Obs.: A leitura desses planos diretores implicou numa análise eminentemente qualitativa.

A Tabela 2, apresenta dados da pesquisa em andamento, da Rede Nacional de Avaliação e Capacitação para Implementação dos Planos Diretores Participativos, que tem por objetivo avaliar os Planos Diretores Participativos elaborados no Brasil, coordenada em Goiás pelo núcleo do Observatório das Metrópoles. Observa-se, que em relação à gestão participativa, os planos diretores em questão apresentam poucos mecanismos de participação; todos prevêem a participação social na formulação das políticas, planos e projetos de desenvolvimento urbano e instituem conselhos ligados à política urbana, restringindo, entretanto, a participação social aos mecanismos colegiados. Espaços públicos fundamentais para a educação política e para a afirmação democrática, como as audiências e as consultas públicas, são ignorados, à exceção do Plano Diretor de Aparecida de Goiânia. A articulação entre os conselhos gestores, outro mecanismo fundamental para a garantia de efetividade das políticas urbanas, não foi considerada em nenhum dos planos.

Outrossim, é importante destacar que o Orçamento Participativo, enquanto espaço público de democratização da definição da aplicação dos recursos públicos no território, não foi mencionado por nenhum plano, sendo que os mesmos preservaram, 
quanto ao sistema de gestão e participação democrática, um viés eminentemente ortodoxo, conservador e anti-popular, salvo, mais uma vez, ligeira vantagem instituída no PD de Aparecida de Goiânia. Por mais que tenham sido produzidos sob o signo de "participativos" ou "democráticos", contando mesmo com a participação social, mesmo que de forma relativa, em sua elaboração, tais planos não expressam esses fundamentos. Expressam sim, a incapacidade da população da RMG e, em especial Goiânia, de lidar na atualidade com esse princípio fundamental da cidadania e do gozo de direitos.

\section{Conclusão}

Este trabalho implicou num exercício de aproximação que tentou demonstrar a íntima relação entre a questão urbana e a questão política. A primeira centrada nas contradições que demarcam o espaço segregado da metrópole atual, e a segunda focada na mobilização coletiva em torno das decisões sobre o futuro da cidade.

A pergunta fundamental, e que o prosseguimento dessa reflexão tentará responder é: na reunião de organizações coletivas em Goiânia, os espaços institucionalizados estão se constituindo em um campo de atuação política fundamental para o futuro da cidade (urbano)? E mais: de que tipo são essas organizações coletivas e qual o sentido vetorial das decisões deliberadas?

A construção de um novo modelo de sociedade, ou seja, de cidade que se quer, passível de ser alcançada dentro dos marcos da institucionalidade, só será possível se houver o envolvimento efetivo do povo em processos de participação a partir do seu lócus de referência - a rua, o bairro, a região, o trabalho, etc. Isto implica em dizer que, de onde quer que as pessoas estejam, uma sociedade pautada num modelo democrático que pretenda a sustentabilidade dentro de um contexto de desenvolvimento integrado, é fundamental a sua organização e participação nos processos institucionais decisórios.

Isto significa que a ampla participação popular faz com que a cultura política de gestão e de intervenção na cidade vá sendo transformada, na medida em que a apropriação da cidade vai se confirmando num processo contínuo de democratização dos espaços públicos. Não obstante, o exercício permanente de cidadania se erige frente à liberdade e à crítica de escolhas e decisões em espaços públicos.

Contudo, as experiências de gestão de Goiânia, principalmente a partir da década 
de 1990, do ponto de vista político-social, não possibilitou grandes avanços para a implantação de mecanismos estáveis de descentralização decisória do espaço urbano, mesmo nas administrações que neste período se apoiaram nos movimentos sociais de recorte popular. Instrumentos utilizados como Orçamento Participativo, Conferência das Cidades e Agenda Goiânia não conseguiram abrir espaço efetivo de participação que possibilitasse a criação de um novo centro de poder, com capacidade de intervenção, em consonância com os respectivos executivos do período, na perspectiva de dar uma feição mais democrática na gestão dos problemas urbanos.

Não obstante, os Planos Diretores Participativos não só não incorporaram a contento dispositivos suficientemente democráticos, no sentido de contemplar uma ampla participação social nos processos decisórios, como também refletem, a partir desta situação, a atual desmobilização por que passa a sociedade civil (especialmente as camadas populares) de Goiânia e sua região metropolitana.

\section{Referências bibliográficas}

ARANTES, Otília. Uma estratégia fatal: a cultura nas novas gestões urbanas. In: ARANTES, O.; VAINER, C.; MARICATO, E. A cidade do pensamento único: desmanchando consensos. $4^{\mathrm{a}}$ edição. Petrópolis: Vozes, 2007.

BONDUKI, N. e KOWARICK, L. Espaço urbano e espaço público: do populismo à redemocratização. In: KOWARICK, L. (org.). As lutas sociais e a cidade. São Paulo: Paz e Terra, 1988. p. 172-199.

BERNARDES, Genilda D'Arc. Goiânia, cidade planejada / cidade vivida: discurso e cultura da modernidade. 1998. 247f. Tese (Doutorado em Sociologia). Brasília: Universidade de Brasília / UnB, 1998.

BORGES, Barsanufo G. A economia goiana na divisão regional do trabalho (19301960). In: SILVA, Luiz S. D. da (org.). Relações cidade-campo: fronteiras. Goiânia: Editora da UFG, 2000. p. 247-272. 
CALDEIRA, T.P.R. Cidade de muros: crime, segregação e cidadania em São Paulo. São Paulo: Editora 34/Edusp, 2000.

CARDOSO, A. L e RIBEIRO, L. C. R. Reforma Urbana e Gestão Democrática: promessas e desafios do Estatuto da Cidade. Rio de Janeiro: Editora Revan, 2003.

CHAUL, Nars N. F. Marchas para o oeste. In: SILVA, Luiz S. D. da (org.). Relações cidade-campo: fronteiras. Goiânia: Editora da UFG, 2000. p. 113-125.

DAHL, Robert. A poliarquia: participação e oposição. São Paulo: Editora da USP, 1997.

GOHN, Maria da G. Associativismo civil, conselhos de gestão na saúde e as cidades brasileiras. in: RASSI NETO, Elias; BOGUS, Cláudia M. (orgs.). Saúde nos aglomerados urbanos: uma visão integrada. Brasília: Organização Pan-americana de Saúde, 2003. p. 155 a 180.

KATZMAN, R. Seducidos y abandonados: el aislamiento social de los pobres urbanos. In: MOYSÉS, Aristides (org.) Cidade, segregação urbana e planejamento. Goiânia: Editora da UCG, 2005. p. 112-130.

KOWARICK, Lúcio. A Espoliação Urbana. Rio de Janeiro: Paz e Terra, 1979.

NOGUEIRA, M. Aurélio. Um Estado para sociedade civil. São Paulo: Cortez, 2004.

OLIVEIRA, Adão F. de. A produção social do espaço. Cultura e liberdade, Goiânia, NUPAC, ano 2, n 2, p. 61-70, abril/2002a.

Do "pântano" ao jardim, uma nova esperança: a produção social do espaço em Goiânia. 2002. 183f. Dissertação (Mestrado em Sociologia). Universidade Federal de Goiás / UFG, Goiânia, 2002b. 
OLIVEIRA, Adão F. de; MOYSÉS, Aristides; CHAVEIRO, Eguimar F.; OLIVEIRA, Ubiratan F. de. Cultura política, democracia e segregação socioterritorial em Goiânia. Goiânia (avulso), 2008.

RIBEIRO, Luiz C. de Q. Segregação residencial: teorias, conceitos e técnicas. In: MOYSÉS, A. (org.) Cidade, segregação urbana e planejamento. Goiânia: Editora da UCG, 2005. p. 131-149.

SANTOS JÚNIOR, Orlando A. dos. Democracia e governo local: dilemas da reforma municipal no Brasil. Rio de Janeiro: Revan / FASE, 2001.

SILVA, Luiz S. D. da (org.). Relações cidade-campo: fronteiras. Goiânia: Editora da UFG, 2000.

VILLAÇA. F. Espaço intra-urbano no Brasil. São Paulo: Studio Nobel, 1998.

Recebido para publicação em janeiro de 2010 Aprovado para publicação em agosto de 2010 